This is an Author's Accepted Manuscript of an article published as: LOPES, H. (2011) Why do people work? Individual wants versus common goods. Journal of Economic Issues, 45(1), 57-74 available online at: http://www.mesharpe.com/ DOI http://dx.doi.org/10.2753/JEI0021-3624450104 


\title{
Why Do People Work? Individual Wants Versus Common Goods
}

\author{
Helena Lopes
}

\begin{abstract}
Empirical evidence strongly suggests that something other than pay is sought in work. By emphasizing consumption over production, the worker as a producer was eclipsed by mainstream economics and replaced by the worker as a consumer. The analysis of the relational dimension of work life was also discarded. We argue that the decision to work and behavior at work is very much driven by the search for relational goods and moral goods, defined as intangible entities that emerge from social interactions. The "goodness" of relational and moral goods stems from their being commonly shared. Two properties of both goods commonality and immanence-in-action - rule out the possibility of their being captured in a utility maximizing framework.
\end{abstract}

Keywords: common goods, moral goods, relational goods, working environment

JEL Classification Codes: J01, J28, J32

Everyone who is worth anything carries his higher nature with him into business; and, there as elsewhere, he is influenced by his personal affections, by his conceptions of duty and his reverence for high ideals.

- Alfred Marshall ([1890] 1966)

Most people rate satisfying work as more important to personal happiness than the level of income (Lane 1992). Good relations with co-workers are the most referred source of job satisfaction among workers from all age groups: "the largest impact on overall job satisfaction comes from having good relations at work" (Organization for Economic Cooperation and Development [OECD] 1998, 14). Also, the desire to have some paid work irrespective of financial needs is more frequent among unemployed than employed people (Gallie and Paugam 2000). 
These findings demonstrate that something other than pay is sought in work and strongly suggest that the relational dimension of work is particularly valued. These phenomena cannot be adequately explained by the standard microeconomic model of labor supply, which portrays work as a source of disutility and as an instrumental activity for the sole purpose of earning an income. The aim of the present paper is to challenge the view of mainstream economics by contending that work provides people with the opportunity to satisfy needs that are essential for their well-being.

A number of eminent economists, most notably Marx, Marshall and Commons, have emphatically pointed out that under appropriate circumstances work is undertaken not only to access consumption but because it is a potential source of personal achievement and self-realization. While these scholars focused on the intrinsic qualities of work content itself, we are more specifically concerned with the social and interpersonal relations entered into when people work. By focusing on the relational components of working life the paper intends to contribute to a better understanding of the evidence outlined above. More generally, two questions are addressed: 1) Why do people work? And 2) Why do workers work as hard as they do?

In the last two decades the standard assumption of income as the sole incentive for work has been confronted by a stimulating range of models that propose altruism (Rotemberg 1994); preferences for cooperation (Rob and Zemsky 2002); fairness (Akerlof and Yellen 1990); and identity (Akerlof and Kranton 2005) as non-pecuniary sources of worker motivation and satisfaction. Though all these motives are explicitly associated to social interactions, they are conceived as individual (pro-social) preferences, lumped together with the other arguments in the usual utility functions.

The goal of the present paper is to propose an alternative account of such motives by conceiving them, first, as grounded in the human need for relatedness rather than as preferences and, second, as commonly held goods - relational goods rather than individual desires. It is argued that the disutility assumption rests on a particular conception of well-being that overstates the importance of consumption for human welfare and underrates that of action. The disregard of the category of action has led to the study of both work and social interactions being discarded in economic theory.

Following Uhlaner (1989) and Gui $(2000,2005)$ we define relational goods as entities that emerge from sustained personalized interactions. But we depart from these authors' individualistic stance in arguing that relational goods constitute an instance of common goods, defined here as goods that are shared and recognized as beneficial by the interacting individuals. The "goodness" of these goods stems more from their being commonly shared than from their generating utility.

The paper is structured as follows. Section two briefly presents the disutility assumption - or its absence - and highlights the fact that mainstream economics neglects the role of human needs and discards the study of work because it is grounded on a conception of well-being focused on leisure and consumption. Carrying the argument forward, section three suggests that the neglect of the category of action, associated with the emphasis on consumption in detriment of production, 
led economists to overlook the relational dimension of work life. Section four introduces and develops the notions of relational and moral goods, conceived as common goods, which we argue strongly underlie the decision to work and behavior at work. Section five draws some normative considerations from the analytical argument and section six concludes.

\section{The Theoretical Foundations of the Disutility Assumption - Or of Its Absence}

Most schools of economic thought, with Marx and the early institutionalists as major exceptions, emphasized the negative aspects of work; labor has been seen primarily in economics as a source of pain (Spencer 2009). In the late nineteenth century, Jevons introduced the notion of the "disutility" of work - which he considered could be either positive or negative depending on work's qualitative content. Soon after, because early Austrian economists wanted to establish utility as the exclusive source of value, they dispensed with the disutility concept and replaced it with the notion of the opportunity cost of work time. Workers would resist work not because of the displeasure of work but because of the benefits of leisure time. It is this latter conception that still underlies the neoclassical models of labor supply, framed in terms of a leisure-income trade-off from which labor disappeared. The omnipresence of labor in the works of the Classics was replaced by its conspicuous absence in the standard neoclassical model (Derobert 2001).

In the last decades of the twentieth century, the disutility assumption reappeared in organizational and personnel economics in the form of effort avoidance. The standard labor supply models, in which the extraction of effort was taken for granted, were followed by agency models which postulate that most workers are opportunistic individuals who resist effort and shirk whenever possible. ${ }^{1}$ Due to the irreducible incompleteness of labor contracts, workers possess some discretion over their level of effort. Both this discretion and their shirking instinct are to be contained by monitoring arrangements and incentive-compatible devices.

It is the link between utility and consumption that forcefully guides economic theorizing. Gratifying experiences would be precluded to economic agents within work organizations; their proper place would be "that other black box, the household" (Demsetz 1995, 12). Utility would be experienced at the level of leisure and consumption alone and hence outside productive contexts. The exclusion of the study of work from the realm of economic analysis goes hand in hand with the separation between consumption and production and the supremacy of consumption over production proclaimed by some early marginalists.

The theory of compensating wage differentials (Rosen 1987) represents the sole attempt, within recent neoclassical labor economics, to account for potentially positive or negative effects of work on workers' utility. This theory seeks to extend the conventional model of labor supply by including a variable in the worker's utility function that captures the worker's preferences for work. The utility/disutility that workers derive from work is revealed through the workers' willingness to accept 
reduced or else demand increased wage levels. Labor market transactions are then viewed as a tied sale in which the worker simultaneously sells the services of his labor and buys the attributes of his job. As in the conventional model, work is reduced to a matter of wage determination. The difference is that in the theory of compensating wages, workers derive utility from certain features of work - not from work as a whole - to which prices are assigned. Labor supply is still viewed as a special case of consumer theory.

Though having himself been a preeminent promoter of utility theory, Marshall forcefully stressed that "it is the science of activities and not that of wants ... Which . . . may claim to be the interpreter of the history of man" (Marshall [1890] 1966, 116). Marshall believed that certain types of activity are pursued not for ulterior motives but as ends in themselves. He therefore refused to make a theory of consumption the "scientific basis of economics." The qualitative features of work and their effects on the motivation as well as "character" of workers are given strong emphasis in his work. Marshall insisted that the primary task of economists is to develop a theory of activities, because he was convinced that the character of individuals is changed by the conditions in which they live and work - views that we entirely share. Early institutionalists also vehemently challenged the neoclassical view, highlighting the fact that work is not simply a means to consumption; work can also be, and indeed ought to be, a privileged means for human flourishing (Spencer 2009).

However, in most strands of neoclassical economics, work is not valued and sought for its own sake; it is instead perceived merely as a means to the "real" end, consumption. The worker as a producer is thus eclipsed from economic theory, along with labor, and replaced by the worker as a consumer. ${ }^{2}$ Only leisure and consumption would be likely to enhance the welfare of individuals. This perspective fundamentally misconstrues the reasons why people supply labor.

What in fact underlies the neoclassical economics perspective on work is a particular conception of well-being, namely the "hedonic" approach. The latter takes well-being to be dependent on individual utility - that is, on preference fulfillment and focuses on pain avoidance and pleasure seeking. Conversely, the "eudaimonic" approach conceives well-being as an active process understood in terms of human flourishing, of what people are able to be and to do. "It is the characteristic of man to do something, not only to suffer the pleasures and pains through the impact of suitable forces. He is not simply a bundle of desires . . ., but rather a coherent structure of propensities and habits which seek realisation and expression through unfolding activity" (Veblen, in Kaufmann 1999, 371-372). The conception of wellbeing in neoclassical economics led to the disregard of the fact that activity plays a major role in human happiness. ${ }^{3}$ However, the road to happiness goes through the work domain every bit as much as the consumer domain (Lane 1992). Activity, relationships with others and self-determination are acknowledged by philosophers and psychologists to be among the most intrinsically valuable areas of human life. 


\section{Choice Versus Action}

Labor supply models, like all economic models, portray a choice over actions based on the evaluation of the utility derived from the consequences of alternative actions. In this framework, actions are conceived in a strictly instrumental fashion: they are (reduced to being) the means through which agents bring about a future increase of welfare. Choice is defined as action selection and it is choice (or decision-making), not action, that constitutes the central object of standard economic analysis. The study of the formation of "preferences," upstream of choice, and that of actions, downstream, are simply considered to be out of the domain of economics (Kaufmann 1999).

However, the notions of choice and action differ deeply in nature. Choice is a cognitive process that takes place within the person while action is a physical process that occurs in the outside world, which it always transforms. As the neoclassical models typically assume that the action undertaken by the agent will result in the desired outcome, the two terms are actually used interchangeably in most of the economists' writings. The supposed ability of the rational decision-maker to ex ante calculate the optimal solution amounts to removing action from any interest. As put by Chatel and Rivaud-Danset (2006), economic theory ends when action begins. Economics looks at the world from the point of view of a choosing rather than an acting agent. There is therefore nowhere left in neoclassical economics to account for the actions per se nor to analytically distinguish between choice and action. ${ }^{4}$ Agents are hedonic beings confronted with choice options, not producers involved in active endeavors. Nonetheless, the consideration of action as opposed to an exclusive focus on choice may prove crucial to understanding behavior at work.

In our societies, people work to earn a living but the psychological needs work can satisfy (if it is suitably organized) are of equal importance. Standard economics, including compensating wages theory, represents well-being in terms of preferences, thus equating all needs to preferences. Yet needs must be distinguished from desires, wants or preferences: "needs specify psychological nutriments that are essential for ongoing psychological growth, integrity, and well-being" (Deci and Ryan 2000, 229). Whereas the satisfaction of desires, which are subjectively felt, yields more or less momentary pleasure, needs are objectively rooted and their satisfaction determines human growth.

The first studies on human needs postulated a hierarchical pyramid stretching from basic physical needs at the bottom to spiritual needs at the top. More recently, the different sets of needs - material, social and moral - are rather placed on a more or less equal footing (Jackson and Marks 1999). There are some resonances between the social psychological categorizations of needs and Hannah Arendt's (1958) three forms of human activity: labor, work and action. The needs of subsistence and protection would be satisfied through labor, the term used by Arendt to designate the repetitive and never-ending activities in which humans must engage to sustain the physiological requirements of life. The needs for self-realization and creation would be satisfied through work, the term that designates the activities through which humans transform the physical world in which they live. Finally, action is driven by the need to 
live a good (in ethical terms) and meaningful life. Action refers more specifically to the activities involved in our living together.

Indeed, a key feature of action is plurality (plurality of persons), that is, action does not take place in isolation from others. Without the presence and acknowledgment of others, there would be no meaningful action. In Arendt's conception, ${ }^{5}$ action is related to the existence of a common world, a world shared by all the members of a community, beyond personal appropriateness. Arendt relates action and the common world to the "affairs that go on among those who inhabit the world together" because "it is not Man but men who inhabit the world" (Arendt 1958, 48). Only by acknowledging plurality can one acknowledge both human singularity and the existence of commonalities. It is by virtue of plurality that each individual is capable of acting and relating to others in ways that are unique and distinctive. The common world is made of all the interactions that take place between humans as well as of the physical environment and the institutional arrangements that powerfully determine and regulate these interactions.

Analyzing economic behavior in terms of choice obscures the fact that, unlike the private character of choice, action is an act undertaken among and often with others. Arendt's notion of action is hence grounded on a radically distinct ontology from that of the rational choice atomistic framework in which agents are defined in terms of their preferences. For Arendt as for most social scientists, humans are constitutionally made to live together with others, to have affective bonds and to deal communicatively with them. It is only through interactions with others that a person can come to see him or herself as an autonomous and an individuated being (Honneth 1995).

Within this framework, actions and interactions are valued and valuable for their own sake. In the sphere of work too, actions and interactions are ends in themselves rather than just instrumental means to attain consumption. Burawoy (1979) provides a vivid illustration of the workers' need to give meaning to their often dull activities. He shows how workers conceive and engage in work games. Workers come to work because they are coerced by their need to earn a living but, at work as well as out of work, individuals transform their activities as far as possible into personally and socially rewarding endeavors. The "games" in which workers engage constitute an instance of the human need for action.

In much the same way as the study of work had been removed from economic analysis, interactions with others had been expelled from the domain of economics by the early marginalists. Economics was to deal with the "lowest range of feelings" because the higher calculus of moral right and wrong was impossible to formulate mathematically (Castro Caldas, Costa and Burns 2007). However, social and moral motives have been progressively reintegrated into mainstream models in the form of arguments incorporated in the utility functions (Akerlof and Kranton 2005; Akerlof and Yellen 1990; Rob and Zemsky 2002). For instance, agents choose to behave fairly toward others because they derive utility from their relationships with others or because they seek to avoid moral disutility (guilt, shame). Together with pecuniary preferences these models endow economic agents with affective and moral preferences. 
Likewise, some compensating wages models incorporate in the worker's utility function a variable that captures the worker's social preferences. The relational satisfaction a worker derives from a particular job would be compensated by a reduced wage level. This way of reintroducing the social motives into the workers' decisions raises serious concerns, though. Firstly, affective states are not preferences, "they are not, as preferences are, comparative relations among objectively described options; rather, they are our subjective experiences of the world" (Sugden 2005, 54). The latter influence the process of preference formation and hence cannot be assimilated to preferences. Secondly, relatedness is a (social) need; a need is a necessity, not a preference. Unlike preferences, needs do not satisfy the conditions of continuity and non-satiation that ground the rational choice model (Kaufmann 1999). Thirdly, there is a problem of incommensurability: social needs and pecuniary preferences are of a different nature and the extent to which they might be compared and traded against each other is problematic. The goods that emerge from social interactions are goods but not commodities; they are valued because they respond to a need but they cannot have a market price. The theory of compensating wages implies that the worker attributes a price to his emotional and moral well-being. There would be an implicit market on which relational and moral satisfaction would be traded. For instance, emotional harassment and moral corruption would have a price. Though this may sound innocuous for some neoclassical scholars, this theoretical rationale raises deep philosophical issues.

In mainstream accounts, personal and social relations result from individualistic and instrumental calculations. People would relate with others and follow behavioral norms because this enhances their short or long-term private interest. In contrast, the approach defended here understands relationships with others as valued for their own sake. Affective states and moral norms have been incorporated into the utility calculations without any revision of the underlying ontological conception and without any acknowledgement of a "common world." However, much of work activity is carried out by social agents in cooperation, in a space of common action. The models that frame work decisions in terms of individual utility-maximization are unsatisfactory. Rather, behavior at work should be conceived as an instance of the broader category of human action, which implies going beyond the utility-maximizing individualistic framework. Our intent hereafter is to argue that most workers do provide effort and do cooperate with each other because they pursue common goods in work.

\section{Relational and Moral Goods}

Our argument is that the decision to work and behavior at work is motivated by the quest for relational goods - as well as the desire and need to earn a living - because relatedness is a major human need (Deci and Ryan 2000, 231). Satisfying interpersonal relations are crucial to developing a positive self-image (Honneth 1995). That is, relationships with others are valued and sought not just for the satisfaction they yield but because they are a part of eudaimonia - without them individuals cannot flourish and realize their true potential. 


\section{Relational Goods}

Relational goods are the outputs of a relational (cognitive, communicative and affective) nature created by interpersonal relations (Bruni 2008; Gui 2000, 2005; Uhlaner 1989). They emerge from human interactions in which the identity of the participants as particular human beings has affective and/or cognitive significance. Relational goods constitute intangible entities, jointly created by the relation between oneself and particular others, that are valued by the participants because they satisfy the human need for relatedness.

Relationships (with colleagues and superiors) have been shown to explain job satisfaction more than economic benefits (OECD 1998; Ritter and Anker 2002). There is overwhelming evidence that interacting with other people and having good interpersonal relations at work have positive consequences on both job satisfaction and employee performances (Rotemberg 2006). When interpersonal relations are poor, job satisfaction is low, regardless of the wage level (Borzaga and Depedri 2005). The relational motive has also been put forward as the main motive for volunteer work (Prouteau and Wolff 2008).

The term relational "goods" is used here as a generic designation. The intangible entities we term relational goods may in fact be "bads" depending on the way the interpersonal interactions evolve and on the conditions in which they take place. As pointed out by Gazier and This Saint Jean (2005), there is often a "dark side" in interpersonal relations, particularly when power and hierarchy are involved. ${ }^{6}$ On one hand, the relational "bads" that interpersonal relations may generate can be violently destructive for the relational climate at work - through, for instance, spite or a desire for revenge. On the other hand, the existence of relational goods contributes to striking a balance between the competing interests of the different actors of the organization (Budd, Gomez and Meltz 2004).

In contrast to the individualistic underpinning of most current conceptions of relational goods, the commonality involved in relational goods must be pointed out. As referred, we see more in relational goods than mutual derivation of utility. The "goodness" of relational goods stems from their being shared: they are goods because and only if they are commonly experienced and valued.

Relational goods are common goods, defined here as (a) goods attainable only through interaction and (b) goods recognized as beneficial by the interacting individuals. Relational goods at work emerge from the workers' joint actions; they are produced and enjoyed simultaneously, by the interacting workers. It is the fact that they are generated in a shared action that makes them a good. ${ }^{7}$ Also, the valuation of personal relations depends on whether or not the people with whom one is interacting also value them. Relational goods only exist if the interacting individuals recognize them as such. They are more than just a combination of private goods, a matter of converging wants and beliefs: they must be the subject of a common valuation.

The notion of common goods highlights two basic aspects of human action in general and of working activity in particular. Firstly, it epitomizes a departure from 
the conception of the individual as an atomistic person, unconcerned about and unrelated to the rest of the world. As mentioned above, most of work activity takes place among and with others. Secondly, the notion of common goods is meant to highlight the importance of action itself, the value of which goes beyond its instrumental contribution to the achievement of given goals - the goal of consumption, in the case at hand.

Contrary to the autonomy and independence involved in private goods, relational goods cannot be experienced by isolated individuals. Nor are they the output of a choice, decided upon ex ante; instead, they are a property of the (inter) action itself, of the shared activities and the forms of communication in which people enter. These two properties of relational goods - commonality and immanence-inaction - rule out the possibility of their being captured in a utility maximizing framework.

\section{Moral Goods}

Over the evolutionary history of mankind, the experience of interpersonal and social interactions has formed the ground for judgments of approval and disapproval of own and others' behavior, which have led in turn to the formation of moral norms of conduct. Actions and judgments that are in accordance with the commonly shared norms and values may be conceived as giving rise to "moral goods." Moral goods (or "bads") are then defined as the outputs of a moral nature generated by social interactions.

Two levels of analysis must be distinguished because two different objects are at stake in moral goods: 1) the norm and 2) the interaction itself. Firstly, in order to generate moral goods, the norms underlying the judgments and guiding the actions of the interacting individuals must be commonly valued. We are at the institutional level: norms and values have an existence of their own, which transcend the particular individuals who endorse them. Norms are institutions, mutually held intangible entities constitutive of the common world. Secondly, these norms translate into particular behaviors; they permeate social interactions. Here, we are at the interpersonal level; the phenomenon addressed - the interaction itself - no longer stands beyond or above individuals but rather among and between them. For instance, if worker $\mathrm{A}$ reciprocates a favor to worker $\mathrm{B}$, both $\mathrm{A}$ and $\mathrm{B}$ enjoy a moral good. The latter is generated by B's behavior and by the fact that both A and B endorse the norm of reciprocity. That is, social interactions give rise to moral goods that are enjoyed by the interacting individuals and owe their existence to autonomous entities, the shared norms and values.

In the work sphere, moral goods derive from being treated with justice and enjoying autonomy at work. Indeed, the need for self-determination, like that of relatedness is also a basic human need (Deci and Ryan 2000). To the extent that autonomy and self-determination are associated with human dignity, they have moral value. Institutional labor economists have long since identified equity and selfactualization as key dimensions of the employment relationship (Budd, Gomez and 
Meltz 2004; Kaufmann 1999). In effect, the effort of workers is often contingent on their views of the justice and legitimacy of the conditions under which they work (Bruton and Fairris 1999). Organizational economists also now acknowledge that making the work self-managed results in enhanced intrinsic motivation and greater organizational efficiency, mostly because it fosters trust and cooperation and lower disciplinary and monitoring costs (Akerlof and Kranton 2008; Rotemberg 2006). Social psychologists also testify that workers mind about procedural justice and highly value having "voice" on work-related matters (Cohen-Charash and Spector 2001). For instance, the fall in job satisfaction of British workers is found to be associated with the decline in personal discretion over job tasks (Green 2006).

Commonality is also a crucial propriety of moral goods. Indeed, the normative appeal of moral norms derives precisely from the individual consciousness that a given norm is shared with others. As referred, moral norms are institutions that both transcend individuals and are individually endorsed by them. Like relational goods, the value of moral norms depends on their being commonly shared and valued. But unlike relational goods, moral norms and values involve impersonal valuation. Their normative force does not depend on the particular individuals with whom one interacts. One acts in an honest or fair way not just because or when those with whom one transacts are held in particular regard. Managers who decide to give more autonomy to subordinates are - or should be - prompted by a need to universally respect the dignity of human beings at least as much as by their possible feelings toward them.

Moral norms and values prescribe actions that may lead a person to acting contrary to his/her self-interest - or the organization's interest, in the case at hand. Acting on principle or virtue may imply acting contrary to one's "self-goal" (Sen 2002) $)^{8}$ and may entail personal or organizational costs. In work organizations, workers and managers consciously consider what they want to do but also what they should do. And, hopefully, they adjust their behavior in light of their moral norms rather than exclusively in terms of their own goal or the organization's goal.

In most organizations, and particularly in for-profit organizations, powerful constraints are at stake, which may increase the moral dilemma but also give reasons to elude it. The employers' objective is to obtain the maximum effort from workers rather than maximizing the workers' welfare but the attainment of this very objective constrains employers to behave and organize work in accordance with basic principles of justice and fairness (at least when the macroeconomic situation is not strongly adverse to workers). As illustrated by Burawoy (1979) the elicitation of effort cannot exclusively rest on coercion; employers must incite workers to willingly cooperate with the organization. Organizational life is hence pervaded by a complex combination of conflict and consent, that is, a balance between the competing interests of workers and managers must be sought (Budd, Gomez and Meltz 2004). To the extent that autonomy and allocative and procedural justice form the very heart of a decent employment relationship, such a balance requires reliance on and promotion of moral goods. At another level, the resolution of the unavoidable conflicts among workers, especially in a context where efficiency is deemed to rely on competition, is heavily dependent on the nurturing of relational goods. 
It must be kept in mind, however, that relational and moral goods themselves may be the drivers of conflict and social disruptiveness. Interpersonal disagreements may trigger a spiral of disputes and greatly prejudice well-being of workers and organizational climate. Likewise, the divergence of conceptions on justice principles or on the terms of their application to particular circumstances (not to mention their disregard or manipulation on the part of managers) may lead to negative reciprocity and irreversible relational damages.

To sum up, moral and relational goods are intrinsically related: no relational goods will ever be sustained without trust, reciprocity and loyalty, that is, morally driven behavior. However, as argued, relational and moral goods are of a different nature. Relational goods emerge from personalized relations; they are common in the sense that they are intersubjectively experienced. Note however that this intersubjectivity cannot be reduced to that experienced by the atomistic agents of game theory: in seeking and cultivating relational goods, agents pursue the common goal of affirming and reinforcing their ties rather than the strategic goal of maximizing their individual utility. In contrast, moral goods involve an intersubjective but also institutional dimension. Moral norms are institutions, that is, normative patterns that define what are the proper and legitimate modes of action and which depend on the support of the moral sentiments of the members of society (Hodgson 1988, 123-124). Moral goods are common in that they are in the common reference world; they are constitutive of the social matrix in which individuals find themselves and act.

These two common goods constitute strong drivers of behavior at work; their consideration allows us to account for evidence that cannot be explained by mainstream models. The desire to work irrespective of financial needs cannot be accounted for without considering the need for relatedness and the related search for relational goods. Neither can cooperative behavior ${ }^{9}$ in work organizations be explained without considering the role that relational and moral goods play in motivating and sustaining cooperation (Lopes, Santos and Teles 2009). The decision whether to work and behavior at work can only be clearly explained by the need of humans to relate with one another and lead a meaningful life. The prevalence of consent and cooperation in the workplace, on which capitalist societies rely to such a great extent, depends on the existence and nurturing of relational and moral goods.

\section{Normative Implications}

Normative implications always follow from theoretical claims. If one assumes that workers generically dislike effort, nothing but incentives and control-and-command devices can be recommended to motivate them. Conversely, if one assumes that workers look for a plurality of goods at work, as is claimed in this paper, a key role must be accorded to the content of work and the quality of working life. Acknowledging that a person's integrity is constitutively dependent on his/her relationships with others implies that having the opportunity to develop relational and moral goods should be considered a social right that must be provided for in workplaces. 
Mainstream labor economists have devoted much attention to wages and the number of hours of work but other aspects of work have been subject to far less examination. In particular, Marshall's and the labor institutionalists' concerns about the fact that the conditions in which people work influence the formation of "the noblest qualities of human character" have been largely overlooked.

Rob and Zemsky's (2002) attempt to elucidate the formation of endogenous work preferences, for instance, is laudable. Their model shows how firms may induce workers to cooperate rather than allocate all their time to individual tasks (which are the only ones rewarded). However, their model, like many other mainstream models, focuses exclusively on the extent and intensity of incentive devices. Though workers are endowed with cooperative preferences driven by reciprocity - the utility from helping others increases with the amount of help one has received in the past - the conditions required for sustaining and nurturing the "preferences for helping" are neither acknowledged nor attended to.

Putting the relational components of work at the forefront leads to strongly advocating governance models that explicitly aim at creating the conditions for the development of relational goods and the activation of moral norms. Our approach hence calls for a greater scope for workers' autonomy and participation. Recent mainstream strands of literature such as happiness, behavioral and personnel economics also provide a basis for advocating the promotion of trust, teamwork and participation. It is acknowledged that the exclusive reliance on financial incentives, sanctions and monitoring, generates perverse effects and crowds out work motivation (Frey 1999; Reeson and Tisdell 2008). But the mainstream accounts always rest on individualistic motives: agents cooperate for instrumental reasons. "Ego establishes a relation with alter only when and if the one needs the other, and the counterpart is seen only as a means in order to achieve some goal that is external to the relation itself" (Bruni 2005, 226). In contrast, our approach emphasizes the fact that relational and moral goods are intrinsically and objectively "good" and they are so only because they are shared and commonly experienced. This difference of views cannot but have an impact on the way work is organized.

The nurturing of relational and moral goods is undermined by hierarchical pressures and imposed external rules. Giving workers the possibility to plan and control what they are doing and how is central to their well-being and their flourishing (Brown et al. 2007; Green 2006). However, institutional arrangements conducive to feelings of justice and legitimacy may effectively be at odds with the employers' purposes. For instance, granting workers greater decision-making power which enhances procedural justice and legitimates managerial authority - may prompt decisional and distributional consequences that employers wish to avoid (Bruton and Fairris 1999).

Besides, systems of "employee voicing" and high degrees of normative control are often implemented to avoid unionization and create illusory "commitments" that bind employees' hearts and minds to the corporate interest (Bamberger and Meshoulan 2000). Strong corporate cultures aimed at building shared values and organizational identification may result in some form of organizational tyranny. In the 
same vein, the flip side of increased commitment and empowerment is greater personal accountability, time pressure and intensified systems of appraisal. Selfsurveillance and enhanced work ethic are often a substitute for more conventional disciplinary control, which may perpetuate oppression in the name of overcoming it (Alvesson and Willmott 1992).

From this perspective, worker participation programs can induce work groups to move from interest solidarity to self- and hetero-surveillance. In fact, all governance practices, even when well-intentioned, may have counterproductive effects and be subject to perverse use. A way out of this is the promotion of the collective dimension of work and the establishment of effective workers' representative bodies. Collective bargaining, unions and work councils are among the institutions that can reliably foster both equity and voice and organizational performance (Budd, Gomez and Meltz 2004). Work councils, for instance, are particularly important for co-determining with managers the daily or weekly work activities; they may also prevent managers from taking advantage of the competition between workers (Bruton and Fairris 1999). The usefulness of government regulation and the most appropriate level at which to organize the workers' representation (whether national or local, for instance) have always been disputed issues in the history of institutional thought (Stabile 1996).

The intensification of work allied to competitive managerial practices has provoked a sharp rise in psychological illnesses at work (Green 2006). The new management criteria have led to the interests of workers being disregarded in favor of those of shareholders and clients. Overall, the feeling of being disrespected, neglected and even humiliated is increasingly reported by workers - with the possible exception of the Scandinavian countries. At the same time, the relational sphere of work interactions with others (peers, supervisors, clients) - has acquired a predominant role in almost all occupations. Put together, these phenomena suggest that the quality of the relational dimension of work has significantly deteriorated. That is, instead of nurturing the development of relational and moral goods, the recent evolution of working conditions is contributing to their steady decline. Only by creating the conditions for individual and collective voice and by formally recognizing the tension between conflict and consent in workplaces can the normative regulative power necessary to keep this kind of problem in check be secured.

\section{Concluding Remarks}

The paper started by briefly tracing the origins and evolution of the notion of the disutility of work. We noted that the study of work was removed from the analytical landscape of economics at the end of the nineteenth century, a trait associated to the discarding of the notion of action, and the emphasis placed on consumption as the primary source of well-being. Driven by their desire, first, to establish utility as the sole source of value and, second, to build economics as a "scientific," axiologically neutral and formalized discipline, neoclassical economics ended up eradicating work from the very analysis of work supply. The worker as a producer was thereafter eclipsed from most mainstream economic theory and replaced by the worker as a consumer. 
However, the evidence shows that the satisfaction of individuals as consumers is not a substitute for their satisfaction as producers. The decision to work and behavior at work are not solely motivated by the desire and need to consume. As highlighted by institutional economists, if organized in the right way, work provides people with the opportunity to satisfy needs essential for well-being, such as the need for selfrealization, the need for relatedness and the need to live a meaningful life.

The desire to work irrespective of financial needs, the providing of effort levels above those strictly required, the pervasiveness of cooperative behavior, cannot be accounted for without considering the relational and moral needs and abilities of individuals. We argue that behavior at work is very much driven by the search for relational goods and moral goods, defined as intangible entities that emerge from social interactions. The view endorsed here is that the "goodness" of these goods stems from their being commonly shared: they are goods because and only if they are commonly experienced and valued by the interacting individuals. In contrast to preferences the main features of relational and moral goods are their commonality and the fact that they are immanent to social practices. These features epitomize a break with the strict privacy and instrumentality of the standard utility maximizing framework.

This paper aims to contribute to a long-standing goal of institutional economists: that of giving account of the commonalities and collective elements that drive agents' behavior. Our elaboration of the notion of common goods tries to avoid the circularity accusation that is often directed at some of the current accounts of shared agency and collective intentionality. However, the theoretical claims made here call for additional analytical investigation. The commonality property of relational and moral goods, in particular, warrants deeper scrutiny and development. Also, the normative implications should be further elaborated.

The reports on the recent evolution of the conditions of work and employment are the cause of great pessimism about the possibility of developing relational and moral goods at work. However, as claimed by Marshall, "a man's character is moulded by his everyday work." The working conditions may hence have a decaying impact on labor and impose profound and irreversible costs on society (Stabile 1996). Labor economists should now revive the concern of Marshall and the institutionalists to responsibly address the quality of working life.

\section{Notes}

1. As pointed out by Spencer (2003), while workers are endowed with a "shirking instinct," employers are, by default, granted immunity from opportunism. Employers act non-opportunistically in the pursuit of profit and the mechanisms of reputation would automatically prevent them from exploiting workers.

2. Hannah Arendt (1958) brilliantly shows how modern societies became "societies of labourers," which is the other side of the coin of their being "societies of consumers." Modern men and women condemn themselves to the cycle of production and reproduction, endlessly producing in order to consume and consuming in order to produce.

3. Contrary to the conventional neoclassical view, recent strands of literature in mainstream economics now acknowledge that activity heavily affects well-being. Some happiness economists, in particular, endorse a eudaimonic, as opposed to hedonic, conception of human well-being. The eudaimonic 
conception, which follows an Aristotelian rather than utilitarian tradition, has always been advocated by institutional economists. It has been recently reintroduced in economics by Martha Nussbaum (2005) and Amartya Sen (2002).

4. The notion of action is pivotal in sociology, political science and philosophy. We do not intend here to carry out a systematic confrontation of the notions of choice and action. We solely point to some of the distinctive features of action as compared to choice.

5. Arendt's readers will rightly point out that our use of Arendt's arguments and categories to elaborate on a conception of work is illegitimate. Indeed, Arendt's aim was precisely to discriminate between the three categories of labor, work and action. Nonetheless, unlike Arendt, we do not restrict the economic realm to a strict instrumentality - rather, our point is to highlight the relational dimension of economic behavior. It is our opinion that whenever persons relate with one another, as is the case in workplaces, a dimension that goes beyond instrumentality is irreducibly present.

6. The considerations developed here deal primarily with the relationships between coworkers. Though the argument may be extended to the relationships between workers and employers, the latter kind of relations involve particularities that must be addressed specially. However, the analysis of work cannot be carried out without taking into account the broader structure of the social relations in which work takes place, that is, the social structures of capitalism.

7. Many workers state that boring and uninteresting tasks are made pleasurable because they are performed with others. The joint action might be unpleasant in itself but carrying it out jointly makes it a relational good. Relational goods are not just reciprocity goods (as viewed by Bruni 2008, for instance) but common goods.

8. Sen's purpose has been to convince economists of the need to distinguish between the various human motives for action: 1) the pursuit of one's welfare, 2) the pursuit of one's self-goal, and 3) the compliance with commitments and moral norms. Abidance with norms does not result from costbenefit utility calculations; moral norms are hence not reducible to the utility-maximizing framework. This reinforces the argument, presented in section three, according to which relational goods and moral goods cannot acceptably be incorporated as arguments in the compensating wage differentials models. Moral norms and ethical principles introduce gaps and instabilities into people's preference rankings (Kaufmann 1999).

9. Cooperation and voluntary effort are hard to observe and hence hard to reward. Both features make them improbable phenomena in a conventional economic world.

\section{References}

Akerlof, George and Rachel Kranton. "Identity and the Economics of Organizations." Journal of Economic Perspectives 19, 1 (2005): 9-32.

"Identity, Supervision and Work Groups." American Economic Review 98, 2 (2008): 212-217.

Akerlof, George and Janet Yellen. "The Fair Wage-Effort Hypothesis and Unemployment." Journal of Economic Literature 40, 4 (1990): 1167-1201.

Alvesson, Mats and Hugh Willmott. Critical Management Studies. London: Sage, 1992.

Arendt, Hannah. The Human Condition. Chicago: University of Chicago Press, 1958.

Bamberger, Peter and Ilan Meshoulan. Human Resource Strategy - Formulation, Implementation and Impact. Thousand Oaks: Sage, 2000.

Borzaga, Carlo and Sara Depedri. "Interpersonal Relations and Job Satisfaction: Social Care Services." In Economics and Social Interactions - Accounting for Interpersonal Relations edited by Benedetto Gui and Robert Sugden, pp. 125-149. Cambridge: Cambridge University Press, 2005.

Brown, Andrew, Andy Charlwood, Chris Forde and David Spencer. "Job Quality and the Economics of New Labour: A Critical Appraisal Using Subjective Survey Data." Cambridge Journal of Economics 31 (2007): 941-971.

Bruni, Luigino. "Hic sunt leones: Interpersonal Relations as Unexplored Territory in the Tradition of Economics." In Economics and Social Interactions - Accounting for Interpersonal Relations edited by Benedetto Gui and Robert Sugden, pp. 206-228. Cambridge: Cambridge University Press, 2005. 
"Back to Aristotle? Happiness, Eudaimonia, and Relational Goods." In Capabilities and Happiness, edited by Luigino Bruni, Flavio Comim and Maurizio Pugno, pp. 114-139. Oxford: Oxford University Press, 2008.

Bruton, Henry and David Fairris. "Work and Development." International Labour Review 138, 1 (1999): 5 30.

Budd, John, Rafael Gomez and Noah Meltz. "Why a Balance Is Best: The Pluralist Industrial Relations Paradigm of Balancing Competing Interests." In Theoretical Perspectives on Work and the Employment Relationship, edited by Bruce Kaufmann. Champaign: IRRA, 2004.

Burawoy, Michael. Manufacturing Consent: Changes in the Labor Process under Monopoly Capitalism. Chicago: Chicago University Press, 1979.

Castro Caldas, Jose, Ana Costa and Tom Burns. "Rethinking Economics: The Potential Contribution of the Classics." Cambridge Journal of Economics 31, 1 (2007): 25-40.

Chatel, Elisabeth and Dorothée Rivaud-Danset. "L'économie des conventions: une lecture critique à partir de la philosophie pragmatiste de John Dewey." MESPI Seminar paper. Université Paris X, 2006.

Cohen-Charash, Yochi and Paul Spector. "The Role of Justice in Organizations: A Meta-Analysis." Organizational Behaviour and Human Decision Processes 86, 2 (2001): 278-321.

Deci, Edward and Richard Ryan. "The 'What' and 'Why' of Goal Pursuits: Human Needs and the SelfDetermination of Behavior." Psychological Inquiry 11, 4 (2000): 227-268.

Demsetz, Harold. The Economics of the Business Firm: Seven Critical Commentaries. Cambridge: Cambridge University Press, 1995.

Derobert, Laurent. "On the Genesis of the Canonical Labor Supply Model." Journal of the History of Economic Thought 23, 2 (2001): 197-215.

Frey, Bruno. Not Just for the Money. Cheltenham: Edward Elgar, 1999.

Gallie, Duncan and Serge Paugam (ed.). Welfare Regimes and the Experience of Unemployment in Europe. Oxford: Oxford University Press, 2000.

Gazier, Bernard and Isabelle This Saint-Jean. "Authority and Power In Economic and Sociological Approaches To Interpersonal Relations.” In Economics and Social Interactions - Accounting for Interpersonal Relations edited by Benedetto Gui and Robert Sugden, pp. 229-249. Cambridge: Cambridge University Press, 2005.

Green, Francis. Demanding Work. Princeton, NJ: Princeton University Press, 2006.

Gui, Benedetto. "Beyond Transactions: On the Interpersonal Dimensions of Economic Reality." Annals of Public and Cooperative Economics 71, 2 (2000): 139-169.

_ _ "From Transactions to Encounters: The Joint Generation of Relational Goods and Conventional Values." In Economics and Social Interactions - Accounting for Interpersonal Relations edited by Benedetto Gui and Robert Sugden, pp. 23-51. Cambridge: Cambridge University Press, 2005.

Hodgson, Geoffrey. Economics and Institutions. Cambridge: Cambridge University Press, 1988.

Honneth, Axel. The Struggle for Recognition - The Moral Grammar of Social Conflicts. Cambridge: Polity Press, 1995.

Jackson, Tim and Nic Marks. "Consumption, Sustainable Welfare and Human Needs." Ecological Economics 28 (1999): 421-441.

Kaufmann, Bruce. "Expanding the Behavioral Foundations of Labor Economics." Industrial and Labor Relations Review 52, 3 (1999): 361-392.

Lane, Robert. "Work as 'Disutility' and Money as 'Happiness': Cultural Origins of a Basic Market Error." Journal of Socio-Economics 21, 1 (1992): 43-65.

Lopes, Helena, Ana Santos and Nuno Teles. "The Motives for Cooperation in Work Organizations." Journal of Institutional Economics 5, 3 (2009): 315-338.

Marshall, Alfred. Principles of Economics. London: Macmillan, [1890] 1966.

Nussbaum, Martha. "Mill Between Aristotle and Bentham." In Economics and Happiness: Framing the Analysis, edited by Luigino Bruni and Piero Porta, pp. 170-183. Oxford: Oxford University Press, 2005.

Organization for Economic Cooperation and Development (OECD). "Measure of Job Satisfaction - What Makes a Good Job? Evidence From OECD Countries." Labour Market and Social Policy Occasional Papers, no. 34, 1998. 
Prouteau, Lionel and François Wolff. "On the Relational Motive for Volunteer Work." Journal of Economic Psychology 29 (2008): 314-335.

Reeson, Andrew and John Tisdell. "Institutions, Motivations and Public Goods." Journal of Economic Behaviour and Organization 68, 1 (2008): 273-281.

Ritter, Joseph and Richard Anker. "Good Jobs, Bad Jobs: Workers' Evaluations in Five Countries." International Labour Review 141, 4 (2002): 331-358.

Rob, Rafael and Peter Zemsky. "Social Capital, Corporate Culture, and Incentive Intensity." RAND Journal of Economics 33, 2 (2002): 243-257.

Rosen, Sherwin. "The Theory of Equalizing Differences" In Handbook of Labor Economics, vol. 1, edited by Orly Ashenfelter and Richard Layard, pp. 641-692. Amsterdam: Elsevier, 1987.

Rotemberg, Julio. "Human Relations in the Workplace." Journal of Political Economy 102 (1994): 685-717.

—. "Altruism, Reciprocity and Cooperation in the Workplace." In Handbook of the Economics of Giving, Altruism and Reciprocity, edited by S.C. Kolm and J. Mercier, pp. 137-148. Amsterdam: Elsevier, 2006.

Sen, Amartya. Rationality and Freedom. Cambridge: Belknap Press of Harvard University Press, 2002.

Spencer, David. "Love's Labor's Lost? The Disutility of Work and Work Avoidance in the Economic Analysis of Labor Supply." Review of Social Economy 61, 2 (2003): 235-250.

The Political Economy of Work. London and New York: Routledge, 2009.

Stabile, Donald. Work and Welfare. The Social Costs of Labor in the History of Economic Thought. London: Greenwood Press, 1996.

Sugden, Robert. "Fellow-Feeling." In Economics and Social Interactions - Accounting for Interpersonal Relations edited by Benedetto Gui and Robert Sugden, pp. 52-75. Cambridge: Cambridge University Press, 2005.

Uhlaner, Carole. "Relational Goods and Participation: Incorporating Sociality into a Theory of Rational Action.” Public Choice 62 (1989): 253-285. 